\title{
Second heart sound after pulmonary arterial banding operation
}

\author{
G. R. Cumming \\ From The Department of Pediatrics, University of Manitoba; and The Department of Cardiology, Health \\ Sciences Children's Centre, Winnipeg, Manitoba, Canada
}

After a pulmonary arterial banding procedure the phonocardiograms of 38 patients were correlated with haemodynamic and angiographic findings. Trventy-four patients had uncomplicated ventricular septal defect, 2 had single ventricle, 5 had transposition of the great arteries, 5 had atrioventricular canal defects, and 2 had coarctation of the aorta and ventricular septal defect. $P_{2}$ was separated from $A_{2}$ by less than 40 ms in 10 of the 11 patients with high pulmonary vascular resistance. Of 27 patients with nearly normal pulmonary vascular resistances and distal pulmonary artery pressures less than $50 / 20 \mathrm{mmHg}(6 \cdot 7 / 2.7 \mathrm{kPa}), 24$ had $A_{2}-P_{2}$ intervals of over $40 \mathrm{~ms}$. A narrow $A_{2}-P_{2}$ interval with a satisfactory band was found in 2 patients with large right-to-left shunts. $A_{\mathbf{2}}-P_{2}$ interval did not change appreciably with age, and this measurement is a useful guide as to the effectiveness of pulmonary artery banding by one year after operation. If this interval is less than $40 \mathrm{~ms}$, repeat catheterization should be carried out as such patients may have persisting pulmonary hypertension and an increased pulmonary vascular resistance.

Most patients have an easily heard splitting of the second heart sound $\left(S_{2}\right)$ after a successful pulmonary banding. Some of the clinical reviews of the banding procedure fail to mention this change in the second heart sound (Dammann et al., 1961; Stark et al., 1969), while others (Takahashi et al., 1968) have noted this splitting of the second sound as a characteristic clinical finding after banding. Aziz, Mesko, and Ellison (1972) stressed the potential value of the changes of the second heart sound after banding and presented data showing that with low pulmonary arterial pressures distal to the band, the split was over $40 \mathrm{~ms}$ while, if the pulmonary arterial pressure was raised, the splitting interval was less than $40 \mathrm{~ms}$. This observation indicated that the phonocardiogram could serve as a noninvasive method for monitoring pulmonary arterial pressures after banding. However, only 17 subjects were studied by the above authors, all but 2 with adequate bands, and all subjects were over 2 years of age. Patients with pulmonary arterial banding have been followed with phonocardiograms for about 15 years at Winnipeg Children's Hospital. The phonocardiographic, haemodynamic, and angiographic findings of 38 banded patients are re-

Received 1 September 1975. viewed to assess the validity of using the phonocardiogram as a guide to the effectiveness of the banding procedure in reducing distal pulmonary arterial pressure.

\section{Subjects and methods}

Only patients in severe distress had pulmonary arterial banding. All had failed to respond to medical treatment. Several were desperately ill at the time of banding and the operation was performed in the presence of heart failure and lung infection. Only those patients who had post-banding cardiac catheterizations with measurement of distal pulmonary arterial pressure and with phonocardiograms obtained within a few months of catheterization are included in the present report. The 38 patients comprise about two-thirds of all the patients banded over a 15-year period. Twentyfour patients had uncomplicated ventricular septal defect, 2 had single ventricle, 5 patients had complete atrioventricular canal defects, 5 had transposition of the great arteries, and 2 had coarctation of the aorta as well as ventricular septal defect. The amount of constriction applied at opertion was based on the cardiac response to banding 
and on the distal pulmonary arterial pressure (measured by pressure transducer in 33 patients and estimated by palpation in the others). An attempt was made to reduce the pulmonary arterial systolic pressure to about $40 \mathrm{mmHg}(5 \cdot 3 \mathrm{kPa})$. The mean band diameter was $7 \mathrm{~mm}$, some infants developed striking cardiac slowing, with reduction of the PA pressures to $40 \mathrm{mmHg}(5.3 \mathrm{kPa})$ and the surgeon accepted a lesser degree of constriction.

An index of pulmonary blood flow was obtained by using the pulmonary/systemic flow ratio. As an index of pulmonary vascular resistance, the pulmonary/systemic resistance ratio was calculated using mean pulmonary arterial and femoral arterial pressures. Serial film angiography was performed on all patients and measurements were obtained as indicated in Fig. 1. The minimal diameter of the pulmonary arterial segment underlying the band was measured; the distance from the pulmonary valve ring to the proximal part of the band, as well as the diameters of the pulmonary valve ring and of the aortic valve ring, were recorded. The average magnification factor in the angiographic system was $1 \cdot 11$, and was about the same for each subject, so that the measurements were not corrected for this distortion. Phonocardiograms were obtained using a Maico microphone at the left sternal edge in the second left intercostal space, using the Electronics for Medicine DR8 recorder in the $120-500 \mathrm{~Hz}$ range. The degree of splitting was obtained by

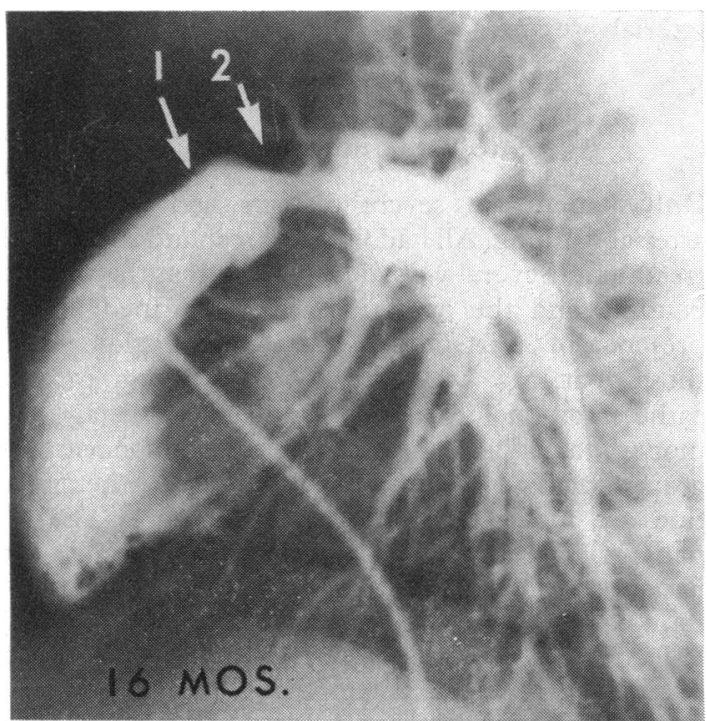

FIG. 1 Angiocardiogram. Arrow $1=$ plane of pulmonary valve; arrow $2=$ level of band. Distance between arrows is distance of band above pulmonary valve ring. averaging the intervals between the aortic and pulmonary components of $S_{2}\left(A_{2}-P_{2}\right.$ interval) for 5 consecutive heart beats. In addition, the height of $P_{2}$ divided by the height of $A_{2}$ was obtained to provide an index of the relative intensities of these sounds. Recorder speed was 75 or $100 \mathrm{~mm} / \mathrm{s}$. In children aged 3 years and over a carotid pulse curve was used to confirm the identification of $\mathrm{A}_{2}$ (Fig. 2).

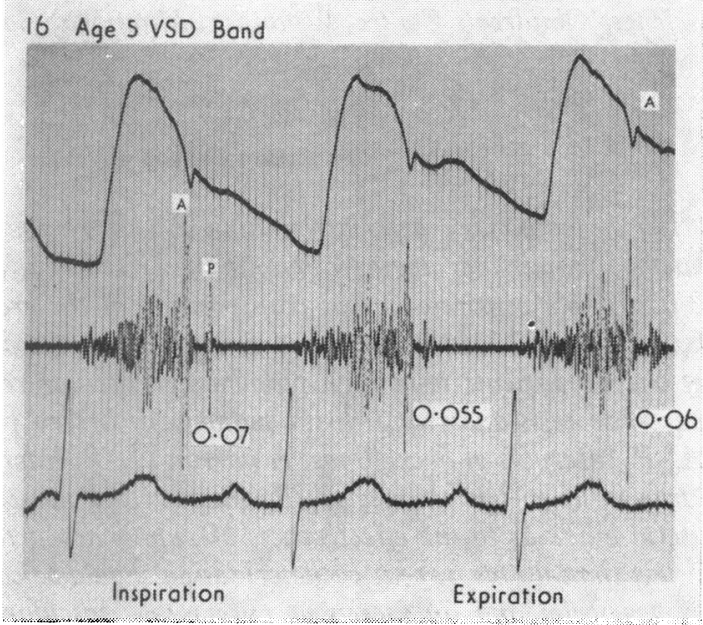

FIG. 2 Case 16-slight change in $A_{2}-P_{2}$ interval with respiration. $100 \mathrm{~mm} / \mathrm{s}$ paper speed, $20 \mathrm{~ms}$ time lines. Use of carotid pulse to identify $A_{2}$. Sharpest and highest deflections arbitrarily used for timing $A_{2}$ and $P_{2}$.

\section{Results}

Of the 38 patients, 15 were 2 years of age or younger, and the oldest patient was 9 years old. The mean age was $4 \pm 3$ years. Individual data are listed in Table 1.

The lumen of the pulmonary artery under the band was $<10 \mathrm{~mm}$ in 29 of the 38 subjects, and $<7 \mathrm{~mm}$ in 16 subjects. The systolic pulmonary arterial pressure was $>50 \mathrm{mmHg}(6.7 \mathrm{kPa})$ in 7 patients; 5 of these had banded segment diameters of $10 \mathrm{~mm}$ or more. The pulmonary/systemic resistance ratio was $>0.30$ in 11 patients and $>0.60$ in 5 of these. In 3 of these latter 5 patients, the banded segment was 10 to $14 \mathrm{~mm}$ in diameter.

Fig. 3A depicts the relations between raised pulmonary artery pressures or pulmonary vascular resistances (expressed as the resistance ratio), and $\mathbf{A}_{\mathbf{2}}-\mathrm{P}_{\mathbf{2}}$ intervals, and Fig. 3B shows similar findings for the ratio of the intensity of $P_{2} / A_{2}$. The values 0.30 for resistance ratio and $50 / 20 \mathrm{mmHg}(6 \cdot 7 / 2 \cdot 7$ $\mathrm{kPa}$ ) pulmonary arterial pressure were chosen arbitrarily. Of the 11 patients with resistance ratios 
of 0.30 or more, the $A_{2}-P_{2}$ interval was $<30 \mathrm{~ms}$ in 7,36 to $38 \mathrm{~ms}$ in 3 , and $45 \mathrm{~ms}$ in 1 patient. Of the 8 patients with pulmonary arterial pressures $>50 / 20$ $\mathrm{mmHg}(6 \cdot 7 / 2 \cdot 7 \mathrm{kPa}), \mathrm{A}_{2}-\mathrm{P}_{2}$ was $<40 \mathrm{~ms}$ in 7 . Of the 14 patients with $A_{2}-P_{2}$ intervals $<40 \mathrm{~ms}$, 11 had raised pulmonary arterial pressures and/or pulmonary vascular resistances (arbitrary values given above). Of the 24 patients with $\mathrm{A}_{2}-\mathrm{P}_{\mathbf{2}}$ intervals of $40 \mathrm{~ms}$ or greater, only 1 had a resistance ratio $>0.30$, and/or pulmonary arterial pressure $>50 / 20$ $\mathrm{mmHg}(6 \cdot 7 / 2 \cdot 7 \mathrm{kPa})$.
The pulmonary component of the second sound was of relatively greater intensity in patients with pulmonary hypertension, but the dividing line between those with raised pulmonary arterial pressures and resistances was less distinct for the ratio of $P_{2} / A_{2}$ intensity than it was for $A_{2}-P_{2}$ interval. Of the 11 subjects with $R P / R S$ ratios $>0.30,8$ had $P_{2} / A_{2}$ intensity ratios of 1.0 or greater. Of the 27 patients with resistance ratios below $0 \cdot 30,22$ of the subjects had $\mathbf{P}_{2} / \mathbf{A}_{2}$ intensity ratios $<1 \cdot 0$. There were similar findings for those subjects with pul-

T A B L 1 Haemodynamic, angiographic, and phonocardiographic data

\begin{tabular}{|c|c|c|c|c|c|c|c|c|c|c|c|c|c|c|c|}
\hline $\begin{array}{l}\text { Case } \\
\text { No. }\end{array}$ & $\begin{array}{l}P_{2}-A_{2} \\
(m s)\end{array}$ & $\begin{array}{l}\text { Age } \\
(y)\end{array}$ & $Q p / Q s$ & $R p / R s$ & $\begin{array}{l}\text { Band } \\
(\mathrm{mm})\end{array}$ & $\begin{array}{l}\text { Band/ } \\
\text { aorta } \\
\text { ratio }\end{array}$ & $\begin{array}{l}\text { Band } \\
\text { distance } \\
\text { ( } \mathrm{mm})\end{array}$ & $\begin{array}{c}\text { Systolic } \\
\text { gradient } \\
(\mathrm{mm})\end{array}$ & $\begin{array}{l}P A P \\
(m m)\end{array}$ & $\begin{array}{l}\text { pressure } \\
H g) \\
D\end{array}$ & $M$ & $\begin{array}{l}\text { Desatu- } \\
\text { ration } \\
(\%)\end{array}$ & $P_{2} / A_{2}$ & $\begin{array}{l}R R \\
(m s)\end{array}$ & Lesion \\
\hline $\begin{array}{r}1 \\
2 \\
3 \\
4 \\
5 \\
6 \\
7 \\
8 \\
9 \\
10 \\
11 \\
12 \\
13 \\
14 \\
15 \\
16 \\
17 \\
18 \\
19 \\
20 \\
21 \\
22 \\
23 \\
24 \\
25 \\
26 \\
27 \\
28 \\
29 \\
30 \\
31 \\
32 \\
33 \\
34 \\
35 \\
36 \\
37 \\
38\end{array}$ & $\begin{array}{r}5 \\
29 \\
20 \\
40 \\
56 \\
48 \\
66 \\
72 \\
65 \\
50 \\
20 \\
24 \\
21 \\
38 \\
80 \\
71 \\
41 \\
46 \\
48 \\
49 \\
61 \\
53 \\
27 \\
33 \\
54 \\
80 \\
55 \\
36 \\
21 \\
55 \\
47 \\
25 \\
36 \\
35 \\
45 \\
60 \\
43 \\
42\end{array}$ & $\begin{array}{l}4 \\
2 \\
5 \\
2 \\
1 \\
2 \\
4 \\
5 \\
4 \\
5 \\
4 \\
6 \\
1 \\
8 \\
5 \\
4 \\
1 \\
1 \\
1 \\
2 \\
2 \\
4 \\
4 \\
4 \\
3 \\
5 \\
5 \\
2 \\
3 \\
8 \\
1 \\
8 \\
9 \\
7 \\
2 \\
1 \\
2 \\
5\end{array}$ & $\begin{array}{l}0.78 \\
0.83 \\
0.74 \\
1.00 \\
0.69 \\
0.97 \\
1.53 \\
1.47 \\
0.65 \\
1.40 \\
0.70 \\
1.25 \\
1.33 \\
1.81 \\
1.14 \\
1.22 \\
1.30 \\
0.71 \\
0.72 \\
2.20 \\
0.89 \\
0.92 \\
0.48 \\
1.39 \\
2.31 \\
1.00 \\
1.70 \\
0.54 \\
1.64 \\
1.90 \\
1.25 \\
0.83 \\
1.56 \\
0.57 \\
0.61 \\
0.90 \\
0.79 \\
1.00\end{array}$ & 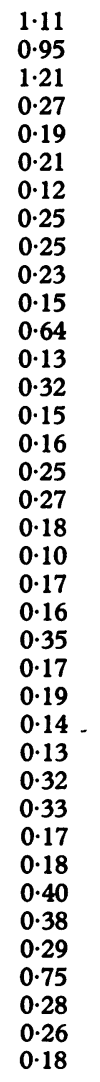 & $\begin{array}{r}11 \\
6 \\
10 \\
7 \\
5 \\
6 \\
8 \\
10 \\
9 \\
10 \\
6 \\
14 \\
6 \\
15 \\
7 \\
4 \\
7 \\
4 \\
4 \\
7 \\
4 \\
8 \\
8 \\
6 \\
9 \\
12 \\
8 \\
4 \\
8 \\
8 \\
7 \\
5 \\
11 \\
6 \\
6 \\
6 \\
4 \\
10\end{array}$ & $\begin{array}{l}0.85 \\
0.40 \\
0.56 \\
0.47 \\
0.31 \\
0.60 \\
0.38 \\
0.42 \\
0.50 \\
0.48 \\
0.35 \\
0.74 \\
0.27 \\
0.79 \\
0.50 \\
0.19 \\
0.47 \\
0.33 \\
0.41 \\
0.42 \\
0.32 \\
0.43 \\
0.40 \\
0.25 \\
0.45 \\
0.36 \\
0.34 \\
0.27 \\
0.43 \\
0.44 \\
0.35 \\
0.31 \\
0.46 \\
0.32 \\
0.32 \\
0.39 \\
0.21 \\
0.67\end{array}$ & $\begin{array}{r}15 \\
15 \\
22 \\
50 \\
8 \\
15 \\
17 \\
30 \\
12 \\
12 \\
17 \\
18 \\
18 \\
13 \\
23 \\
9 \\
11 \\
11 \\
15 \\
10 \\
9 \\
15 \\
16 \\
21 \\
18 \\
30 \\
20 \\
2 \\
16 \\
4 \\
13 \\
17 \\
15 \\
12 \\
7 \\
16 \\
17 \\
30\end{array}$ & $\begin{array}{r}10 \\
64 \\
15 \\
72 \\
80 \\
70 \\
73 \\
62 \\
80 \\
77 \\
92 \\
17 \\
56 \\
12 \\
60 \\
74 \\
54 \\
80 \\
74 \\
64 \\
85 \\
63 \\
86 \\
63 \\
33 \\
83 \\
82 \\
70 \\
35 \\
50 \\
63 \\
45 \\
57 \\
85 \\
51 \\
120 \\
104 \\
48\end{array}$ & $\begin{array}{r}85 \\
46 \\
105 \\
22 \\
12 \\
22 \\
22 \\
34 \\
20 \\
38 \\
15 \\
80 \\
20 \\
83 \\
24 \\
23 \\
36 \\
15 \\
14 \\
26 \\
15 \\
17 \\
21 \\
27 \\
47 \\
20 \\
28 \\
20 \\
55 \\
40 \\
22 \\
37 \\
58 \\
17 \\
54 \\
15 \\
31 \\
18\end{array}$ & $\begin{array}{r}45 \\
24 \\
45 \\
14 \\
7 \\
10 \\
10 \\
11 \\
8 \\
12 \\
9 \\
35 \\
8 \\
28 \\
10 \\
8 \\
12 \\
6 \\
7 \\
11 \\
7 \\
7 \\
12 \\
9 \\
17 \\
8 \\
10 \\
7 \\
22 \\
15 \\
10 \\
11 \\
26 \\
10 \\
30 \\
8 \\
11 \\
8\end{array}$ & $\begin{array}{r}75 \\
36 \\
70 \\
16 \\
9 \\
15 \\
16 \\
20 \\
13 \\
27 \\
11 \\
60 \\
13 \\
47 \\
14 \\
14 \\
24 \\
12 \\
9 \\
18 \\
10 \\
11 \\
17 \\
18 \\
32 \\
14 \\
15 \\
13 \\
35 \\
25 \\
14 \\
22 \\
48 \\
12 \\
38 \\
12 \\
20 \\
13\end{array}$ & $\begin{array}{r}9 \\
24 \\
11 \\
8 \\
6 \\
8 \\
0 \\
4 \\
1 \\
10 \\
10 \\
17 \\
20 \\
1 \\
5 \\
1 \\
6 \\
21 \\
8 \\
20 \\
7 \\
6 \\
15 \\
1 \\
2 \\
16 \\
10 \\
11 \\
8 \\
10 \\
3 \\
25 \\
22 \\
50 \\
42 \\
21 \\
1 \\
0\end{array}$ & $\begin{array}{l}5.10 \\
1.02 \\
6.62 \\
0.58 \\
0.25 \\
0.25 \\
0.31 \\
0.40 \\
0.10 \\
3.00 \\
1.58 \\
2.40 \\
1.13 \\
2.50 \\
0.57 \\
0.28 \\
0.40 \\
0.22 \\
0.65 \\
0.95 \\
0.50 \\
0.24 \\
1.00 \\
1.20 \\
1.08 \\
0.35 \\
0.32 \\
0.14 \\
3.11 \\
0.14 \\
0.21 \\
0.35 \\
0.54 \\
0.05 \\
1.12 \\
0.31 \\
0.96 \\
0.65\end{array}$ & $\begin{array}{l}605 \\
546 \\
773 \\
420 \\
448 \\
395 \\
468 \\
669 \\
560 \\
628 \\
642 \\
746 \\
400 \\
560 \\
540 \\
600 \\
388 \\
448 \\
494 \\
410 \\
495 \\
694 \\
486 \\
438 \\
773 \\
545 \\
739 \\
360 \\
396 \\
620 \\
413 \\
607 \\
672 \\
520 \\
480 \\
533 \\
507 \\
613\end{array}$ & $\begin{array}{l}\text { VSD } \\
\text { VSD } \\
\text { VSD } \\
\text { VSD } \\
\text { VSD } \\
\text { VSD } \\
\text { VSD } \\
\text { VSD } \\
\text { VSD } \\
\text { VSD } \\
\text { VSD } \\
\text { VSD } \\
\text { VSD } \\
\text { VSD } \\
\text { VSD } \\
\text { VSD } \\
\text { VSD } \\
\text { VSD } \\
\text { VSD } \\
\text { VSD } \\
\text { VSD } \\
\text { VSD } \\
\text { VSD } \\
\text { VSD } \\
\text { AVC } \\
\text { AVC } \\
\text { AVC } \\
\text { AVC } \\
\text { AVC } \\
\text { SV } \\
\text { SV } \\
\text { TGA } \\
\text { TGA } \\
\text { TGA } \\
\text { TGA } \\
\text { TGA } \\
\text { COA } \\
\text { COA }\end{array}$ \\
\hline & & $\begin{array}{r}4 \\
+3\end{array}$ & $\begin{array}{r}1.12 \\
\pm 0.46\end{array}$ & $\begin{array}{r}0.32 \\
\pm 0.27\end{array}$ & $\begin{array}{r}7 \\
\pm 2\end{array}$ & $\begin{array}{r}0.42 \\
+0.15\end{array}$ & $\begin{array}{r}15 \\
\pm 6\end{array}$ & $\begin{array}{r}63 \\
+24\end{array}$ & $\begin{array}{r}3 \\
+2\end{array}$ & $\begin{array}{r}14 \\
+10\end{array}$ & $\begin{array}{r}23 \\
+16\end{array}$ & $\begin{array}{r}11 \\
+11\end{array}$ & $\begin{array}{r}1.07 \\
+1.40\end{array}$ & 110 & \\
\hline
\end{tabular}

Age-at time of heart catheterization and phonocardiogram; Qp/Qs-pulmonary/systemic flow ratio; Rp/Rs-pulmonary/ systemic resistance ratio; band/aorta-ratio of band diameter to aortic valve diameter; $\mathbf{P}_{\mathbf{2}} / \mathbf{A}_{\mathbf{2}}$ 一ratio of peak phonocardiographic deflections of $P_{2}$ to $A_{2}$; PA pressure: $S=$ systolic, $D=$ diastolic, $M=$ mean; desaturation-pulmonary vein oxygen saturation (or 96\%) minus arterial; VSD-ventricular septal defect; AVC-atrioventricularis communis; SV-single ventricle; COAcoarctation of aorta (plus VSD); TGA-transposition of great arteries. Cases 32 and 33 also had SV.

Conversion from Traditional to SI units: $1 \mathrm{mmHg} \approx 0.133 \mathrm{kPa}$. 


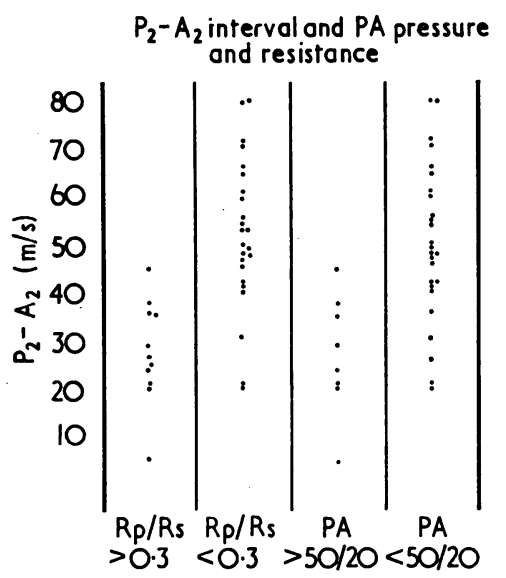

(A)

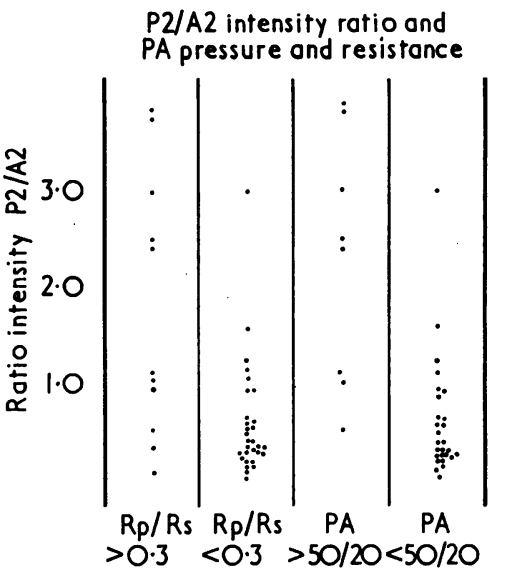

(B)

FI G. 3 (A) $A_{2}-P_{2}$ interval in patients divided into those with high or low pulmonary vascular resistance and those with high or low pulmonary artery pressures. (B) Ratio of intensity of $P_{2} / A_{2}$ in patients divided into those with high or low pulmonary vascular resistance and those with high or low pulmonary artery pressures.

monary hypertension defined as pulmonary arterial pressure $>50 / 20 \mathrm{mmHg}(6 \cdot 7 / 2 \cdot 7 \mathrm{kPa})$.

Four patients had both short $\mathbf{A}_{2}-\mathbf{P}_{2}$ intervals and $P_{2} / A_{2}$ intensity ratios $>1 \cdot 0$, yet had low pulmonary arterial pressures and resistances. Two of these patients had right-to-left shunts of 16 and 29 per cent of systemic flow.

The ratio of pulmonary to systemic blood flow was $>1.5$ in 8 patients. This was not associated with a greater degree of splitting of the second heart sound compared with those with little or no left-toright shunt. The pulmonary arterial pressure was $>40 / 20 \mathrm{mmHg}(5 \cdot 3 / 2 \cdot 7 \mathrm{kPa})$ in 5 of these 8 patients and less than this value in the other 3.

The band was $>15 \mathrm{~mm}$ above the valve in 17 patients, and 11 of these were over 3 years of age. The band was $<10 \mathrm{~mm}$ above the valve in 6 patients and 4 were less than 3 years of age.

Arterial oxygen desaturation was calculated by subtracting the systemic arterial oxygen saturation from the pulmonary venous oxygen saturation. In 14 of the subjects, pulmonary venous saturations were obtained (mean value $96 \%$ ); in the remaining 24 subjects it was assumed that pulmonary venous saturation was 96 per cent. Indicator dilution curves revealed a trace or greater right-to-left shunt in the majority of patients. The desaturation of arterial blood was greater than 8 per cent saturation in 10 of the 24 subjects with uncomplicated ventricular septal defects. In 4 of these 10 subjects the right-toleft shunt was associated with pulmonary hypertension and increased pulmonary vascular resistance, while in the remaining 6 subjects the right-to- left shunt was apparently caused by the narrowness of the band.

Representative phonocardiograms are shown in Fig. 4 to 7. Fig. 4 illustrates the variability in $A_{2}-P_{2}$ intervals and $P_{2} / A_{2}$ intensity ratios in 3 patients with adequate bands. Case 35 with transposition of the great arteries had an $\mathbf{A}_{\mathbf{2}}-\mathrm{P}_{\mathbf{2}}$ interval exceeding $40 \mathrm{~ms}$, but had raised pulmonary arterial pressures. Fig. 5 shows the very loud $P_{2}$ in 2 patients with severe residual pulmonary hypertension. Of 15 patients with phonocardiograms at age 2 to 3 years, and subsequently at least 2 years later at age 4 to 6 years, the mean $A_{2}-P_{2}$ interval changed from 40 to $45 \mathrm{~ms}(P>0 \cdot 10)$ while $R R$ interval changed from 565 to $570 \mathrm{~ms}(\mathrm{P}<0.05)$. There seemed to be little change with age, for the $A_{2}-P_{2}$ interval increased by over $10 \mathrm{~ms}$ in only 3 of the 14 subjects, and the mean values at the two ages were not significantly different. In Fig. 5, Case 25 showed a wider $\mathbf{A}_{2}-P_{2}$ interval with age, and Case 10 no change.

Some respiratory variation may occur in the $\mathrm{A}_{2}-\mathrm{P}_{2}$ interval after $\mathrm{PA}$ banding. The largest variation occurred in Case 38, in whom spontaneous closure of a large ventricular septal defect had occurred during the first year. This girl had an associated coarctation of the aorta, which was not repaired at the time of banding but was electively repaired at age 7 along with removal of the band. At cardiac catheterization at age 5 , the right ventricular pressure was $66 \mathrm{mmHg}(8.8 \mathrm{kPa})$, systolic pulmonary arterial pressure $18 \mathrm{mmHg}(2.4 \mathrm{kPa})$, and left ventricular pressure $134 \mathrm{mmHg}(17.8 \mathrm{kPa})$. The most notable feature of $S_{2}$ was the pronounced 


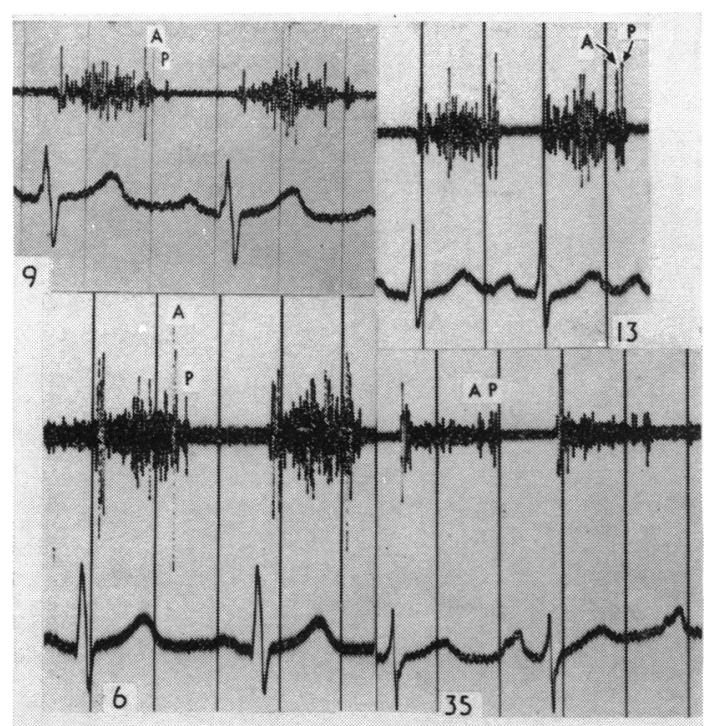

FIG. 4 Phonocardiograms from 4 banded patients. Case 9 at age 4, Case 13 at age 1, Case 6 at age 2 years, all with large ventricular septal defects and normal $P A$ pressures. Variable degrees of splitting of $S_{2}$, variable ratio of intensities of $P_{2} / A_{2}$. Case 35 has transposition of the great arteries and systolic $P A$ pressure was $54 \mathrm{mmHg}(7 \cdot 2 \mathrm{kPa})$. Time lines $0.2 \mathrm{~s}$ in these and subsequent phonocardiograms.

respiratory fluctuation in the $A_{2}-P_{2}$ interval (Fig. 6). In most of the remaining subjects the $A_{2}-P_{2}$ intervals were either constant or changed by $<10 \mathrm{~ms}$ with different phases of respiration. No attempt was made to control respiration during the phonocardiograms on these patients, the majority of whom were under 5 years of age.

Linear regression analyses were carried out for the $A_{2}-P_{2}$ interval and the $P_{2} / A_{2}$ intensity ratios (Table 2). The highest correlation was for pulmonary arterial diastolic pressure and sound intensity ratio, and other significant correlations were found between resistance ratio, the ratio of band diameter to aortic diameter, and systolic pressure gradient across the band.

\section{Discussion}

As experience is gained in operating on small infants with large ventricular septal defects, considerably fewer pulmonary arterial banding procedures will be performed. None the less, in some complex cardiac anomalies, such as single ventricle, transposition of the great arteries, and atrioventricular canal, the banding procedure is likely to remain a useful palliative procedure. It is in some of these patients that it may be difficult to enter the pulmonary artery at catheterization and an indirect means of assessing the pulmonary haemodynamics after banding would be most useful. In the series reported here, 4 patients had an inadequate band. Two of these subjects subsequently had pulmonary systemic resistance ratios of greater than 1.0 , and are considered inoperable. In one subject the pulmonary/systemic resistance ratio was 0.64 and successful closure of the ventricular septal defect was carried out, but four years after operation the patient was in difficulty because of progressive pulmonary vascular disease. While 2 of these 4 patients moved away and were not seen again for 2 to 3 years after the banding procedure, and the parents of a third patient refused further operation, the phonocardiogram correctly identified these subjects as having persisting pulmonary hypertension and might have allowed earlier reinvestigation and effective surgery.

While the correlation between the level of pulmonary arterial pressure or pulmonary vascular resistance and the $A_{2}-P_{2}$ interval was not high, measurement of this interval was of practical importance. All but one of the subjects with a significant increase in pulmonary vascular resistance (pulmonary/systemic resistance ratio $>0.30$ ) had an $\mathrm{A}_{2}-\mathrm{P}_{2}$ interval of less than $40 \mathrm{~ms}$, allowing a recognition of 90 per cent of subjects with an increase in resistance. Of the 27 subjects with normal resistances, 3 had $\mathrm{A}_{2}-\mathrm{P}_{2}$ intervals of $<40 \mathrm{~ms}$, a frequency of 11 per cent false positive identification of patients likely to have an increased pulmonary vascular resistance by using the $40 \mathrm{~ms}$ cutoff value.

The ratio of the intensity of $P_{2} / A_{2}$ was a less reliable index of rise in pulmonary arterial pressures or vascular resistance than was the $\mathrm{A}_{2}-\mathbf{P}_{2}$ interval. Of subjects with an increased pulmonary vascular resistance, 73 per cent had $P_{2} / A_{2}$ sound intensity ratios $<1.0$, resulting in a false negative index in 27 per cent of the subjects. Eighteen per cent of the subjects gave a false positive result having $P_{2} / A_{2}$ ratios of $<1.0$, in the absence of any increase in pulmonary arterial pressure or pulmonary vascular resistance.

One explanation of why the patient with a low pulmonary arterial pressure distal to an adequate band has wide splitting of the second heart sound is that the pulmonary valve does not close until the proximal pulmonary artery pressure falls from its high systolic level to a low diastolic value. 


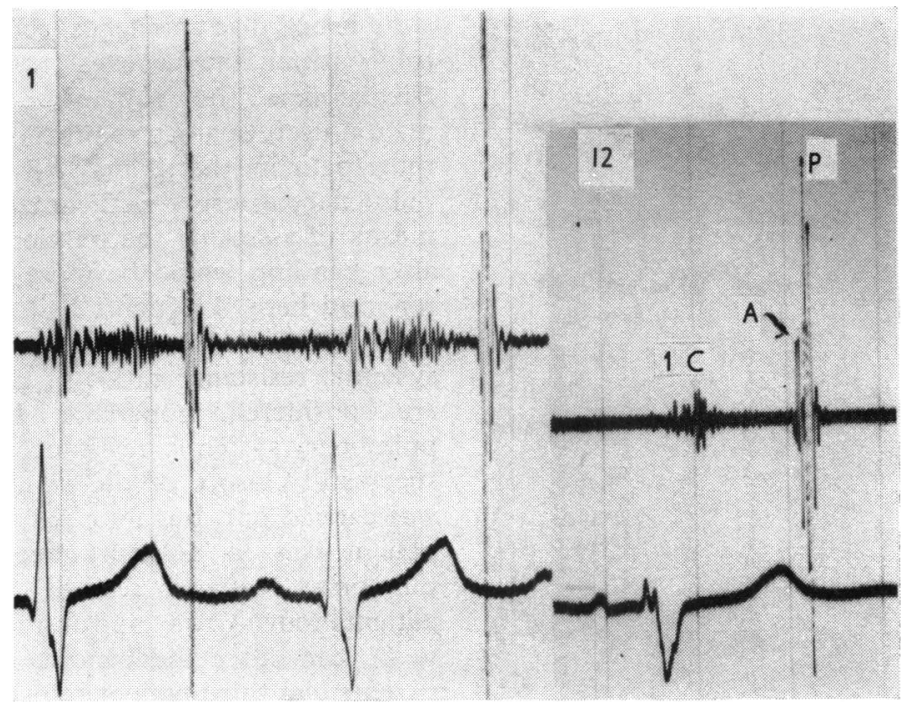

FIG. 5 Two patients with unsatisfactory results with severe persisting pulmonary hypertension. Case 1 -very loud single $S_{2}$; Case 12-systolic ejection click $(C), P_{2}$ is much louder than $A_{2}$ and $A_{2}-P_{2}$ is only $24 \mathrm{~ms}$.

Shaver et al. (1974) recently showed that the $P_{2}$ sound is delayed 33 to $89 \mathrm{~ms}$ beyond that point at which pulmonary arterial pressure falls below right ventricular pressure. Recognition of this time lag (called hangout) was possible with the development

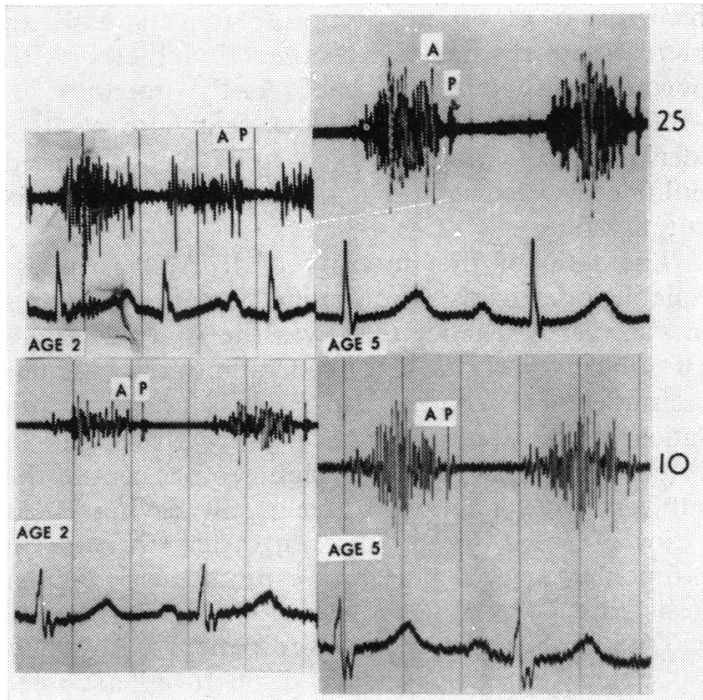

F I G. 6 Phonocardiograms 3 years apart in 2 patients. Case 25- $A_{2}-P_{2}$ increased from 26 to $52 \mathrm{~ms}$. Case $10-A_{2}-P_{2}$ changed very little from 52 to $50 \mathrm{~ms}$. of practical catheter tip manometers. It was reported that the wide splitting of the second sound in patients with idiopathic dilatation of the pulmonary artery, mild pulmonary stenosis, and atrial septal defect, was not the result of prolonged right ventricular systole, but of an increase in this 'hangout' interval. Values for this 'hangout' interval will be of use in inderstanding the wide $A_{2}-P_{2}$ interval in patients with pulmonary arterial banding, but are not available. A reduced pulmonary arterial capacitance present in patients with pulmonary arterial banding might shorten the $\mathrm{A}_{\mathbf{2}}-\mathrm{P}_{\mathbf{2}}$ interval by reducing the $\mathrm{P}_{2}$ 'hangout' while a prolonged right ventricular systole and a low pulmonary arterial diastolic pressure would tend to delay pulmonary valve closure. Other factors likely to modify the $\mathrm{A}_{2}-\mathrm{P}_{2}$ interval include heart rate, distance of the band above the pulmonary valve ring, age, pulmonary blood flow and its ratio to systemic flow, magnitude of right-to-left or left-to-right shunts, closure of the ventricular defect, and respiration. The same subject was not compared at different heart rates, but no correlation was found between the $\mathbf{A}_{2}-\mathrm{P}_{2}$ interval and heart rates of different subjects. Aziz et al. (1972) reported an inverse linear correlation between the distance the band was above the pulmonary valve ring and the $\mathbf{A}_{2}-\mathbf{P}_{2}$ interval, but this correlation was not confirmed in the present study. Age seemed to influence this distance in our patients. Age would also influence the relative degree of constriction produced by the 


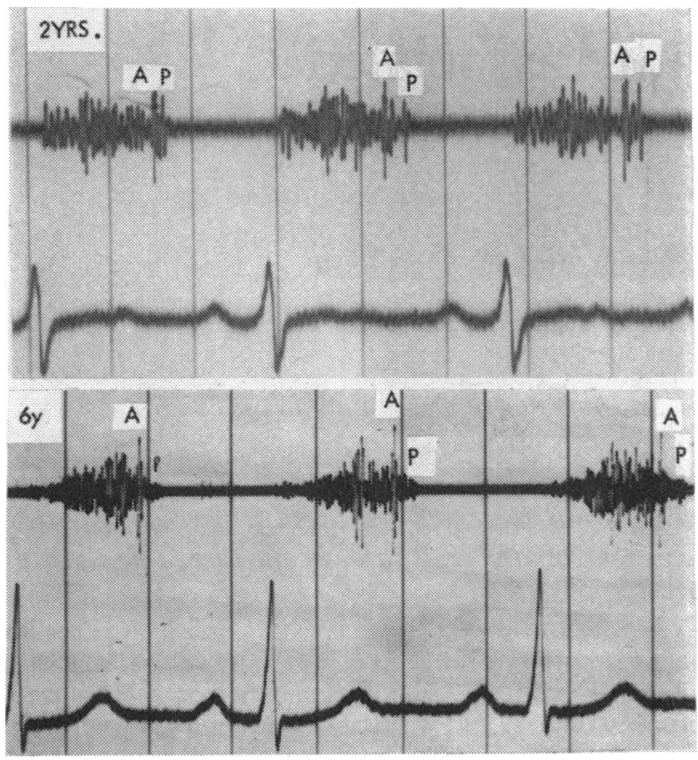

FIG. 7 Phonocardiograms-Case 38 at age 2 and 6 years. There is a striking respiratory variation in the $A_{2}-P_{2}$ interval. The patient had coarctation of aorta and the ventricular defect closed spontaneously.

band, for presumably the band remains fixed while other structures increase in size.

In addition, age might influence pulmonary vascular resistance, and, if previously high, some

TABLE 2 Correlation coefficients $A_{2}-P_{2}$ and $P_{2} / A_{2}$

\begin{tabular}{llll}
\hline & $\begin{array}{c}A_{2}-P_{2} \\
\text { All patients } \\
(38)\end{array}$ & $\begin{array}{l}A_{2}-P_{2} \\
V S D \\
(26)\end{array}$ & $\begin{array}{l}P_{2} / A_{2} \\
\text { All patients } \\
(38)\end{array}$ \\
\hline Qp/Qs & 0.18 & 0.19 & - \\
Rp/Rs & $-0.58^{\star}$ & $-0.64^{\star}$ & $0.73^{\star}$ \\
Band width & -0.10 & -0.30 & $0.45^{\star}$ \\
Band/aortic diameters & -0.31 & $-0.44^{\star}$ & $0.54^{\star}$ \\
Band distance & 0.14 & -0.01 & 0.16 \\
Systolic gradient & $0.49 \star$ & $0.54^{\star}$ & $-0.63^{\star}$ \\
PA diastolic pressure & $-0.58^{\star}$ & $-0.66^{\star}$ & $0.81^{\star}$ \\
Arterial oxygen & & & $-0.53^{\star}$ \\
$\quad$ desaturation & -0.29 & -0.06 \\
RR interval & -0.02 & -0.17 & $0.33^{\star}$ \\
\hline
\end{tabular}

$\star \mathbf{P}<0.05$.

Conversion from Traditional Units to SI Units: $1 \mathrm{mmHg} \approx$ $0.133 \mathrm{kPa}$. recession might be expected on the basis of anatomical studies (Dammann et al., 1961). There was no strong correlation between the pulmonary/systemic flow ratio and the $\mathbf{A}_{2}-\mathrm{P}_{2}$ interval in our clinical material except that a short $A_{2}-P_{2}$ interval was found in 2 subjects with normal pulmonary arterial pressures and large right-to-left shunts. The reduced pulmonary flow in these patients might lead to a shortening of right ventricular systole.

Most of the patients studied by Aziz et al. (1972) were over 4 years of age. The important time to know whether a band has achieved the desired result of lowering pulmonary arterial pressures is within 6 to 12 months of creating the band and before there has been any progression of pulmonary vascular disease. The data on the patients presented here suggest that phonocardiography with the measurement of $A_{2}-P_{2}$ interval is an excellent guideline as to the effectiveness of the band, even at age 1 to 2 years. Patients who have $\mathrm{A}_{2}-\mathrm{P}_{2}$ intervals less than $40 \mathrm{~ms}$ one year after banding should have repeat catheterization studies in order to reassess their haemodynamic situation.

All but three patients were operated on by Dr. Colin C. Ferguson, Director of Department of Surgery, Health Sciences Children's Centre of Winnipeg. Some of the measurements were carried out by Dr. Milton Gold. I am also grateful to Dr. V. Chernick, Chairman of Department of Pediatrics, University of Manitoba, for reviewing the manuscript.

\section{References}

Aziz, K-U-D., Mesko, Z. G., and Ellison, R. C. (1972). Assessment of adequacy of pulmonary arterial banding by phonocardiogram. British Heart fournal, 34, 1029.

Dammann, J. F., Jr., McEachen, J. A., Thompson, W. M., Jr., Smith, R., and Muller, W. H. (1961). The regression of pulmonary vascular disease after the creation of pulmonary stenosis. Fournal of Thoracic and Cardiovascular Surgery, 42, 722.

Shaver, J. A., Nadolny, R., O'Toole, J. D., Thompson, M. E., Reddy, P. S., Leon, D. F., and Curtiss, E. I. (1974). Sound pressure correlates of the second heart sound. Circulation, 49, 316.

Stark, J., Aberdeen, E., Waterston, D. J., Bonham-Carter, R. E., and Tynan, M. (1969). Pulmonary artery constriction (banding): a report of 146 cases. Surgery, 65, 808.

Takahashi, M., Lurie, P. R., Petry, E. L., and King, H. (1968). Clinical and hemodynamic effects of pulmonary artery banding. American fournal of Cardiology, 21, 174.

Requests for reprints to Dr. Gordon R. Cumming, Section of Cardiology, Health Sciences Children's Centre, 685 Bannatyne Avenue, Winnipeg, Manitoba R3E 0W1, Canada. 